\title{
Production-oriented Approach in College English Teaching
}

\author{
Yina Wu \\ Xiamen University Tan Kah Kee College \\ Zhangzhou, China
}

\begin{abstract}
Chinese professor WEN Qiufang puts forward a theoretical system of production-oriented approach, which focuses on the big problem of "separation of learning and using" in English learning by Chinese college students, emphasizes the role of production in language learning and introduces the idea of integrating input and output in language teaching. This paper reviews the theoretical system, which consists of teaching principles, teaching hypotheses and teacher-mediated teaching process, compares it with task-based language teaching, applies it to college English teaching, and points out difficulties in the implementation of this production-oriented approach.
\end{abstract}

Keywords-theoretical system; production-oriented approach; teaching principles; teaching hypotheses; teacher-mediated teaching process

\section{INTRODUCTION}

According to Wen Qiufang, the production-oriented approach (hereinafter referred to as POA) originates from “output-driven hypothesis" put forward by Wen Qiufang in 2007 and was revised in early 2014 as "output driver-inputproducing hypothesis". In October of the same year, at the "7th International Conference on English Teaching in China”, it was officially named POA. Wen points out that "production" and "output" are different in that "production" includes interpretation and translation in addition to what "output" includes, which are speaking and writing. Besides, "production" emphasizes both the producing process and the product [1]. College English teaching in China has long been criticized for being time-consuming and inefficient. POA provides a new teaching idea to improve the efficiency of college English classroom teaching in two aspects. As far as the teaching goal is concerned, it takes the production as the starting point, drives the students' enthusiasm for learning, and takes the production as the goal and applies it. In terms of teaching methods, it emphasizes the role of production in language learning and the integration of input and output in language teaching. As a college English teacher, the writer notices great advantages in POA and applies it in class for experiment. The writer then points out the teaching effect of POA and difficulties in the implementation.

\section{THE THEORETICAL SYSTEM OF POA}

The theoretical system of POA consists of teaching principles, teaching hypotheses and teacher-mediated teaching process, which will be reviewed in this part in details and the
POA will be compared with the popular task-based language teaching.

\section{A. Teaching Principles of POA}

The teaching principles of POA include learning-centered principle, learning-using integrated principle and whole person education principle. The learning-centered principle advocates that all activities of classroom teaching should serve the effective learning as opposed to the popular learner-centered principle. The biggest problem with learner-centered principle is that it tends to marginalize the role of teachers in the classroom and expands the role of students. Although teachers are given a variety of new titles such as facilitators, helpers, and consultants, their most important responsibilities are not properly demonstrated; students are considered to be decision makers of the teaching objectives, teaching content, and teaching process. According to learner-centered principle, the teacher only provides students with the opportunity to work in pairs and groups, and the students can construct and master new knowledge through interaction. This principle has also been criticized by some scholars such as Kirschner for not placing emphasis on whether the teaching objectives of each lesson are achieved and whether the students learn efficiently in the classroom [2]. The learning-centered principle maintains that teaching must achieve teaching goals and promote effective learning. Activities in the classroom can take many forms: lectures by teacher, group discussions, pair work, individual presentations, and group presentations, etc. Different forms serve different teaching objectives. The key is that teachers should choose the best form to achieve the teaching objectives and ensure effective learning. From this perspective, when designing each teaching session or task, POA is primarily concerned with what students can learn, rather than simply examining who is speaking in the classroom as studied by Mercer \& Dawes [3].

In the learning-using integrated principle advocated by POA, "learning" refers to input, which includes listening and reading; "using” refers to output, including speaking, writing, interpreting and translating. This hypothesis criticizes the teaching material- centered practices and the disadvantages of separating learning and using. It advocates using while learning, using in learning, and learning in using. In other words, POA advocates a close integration of learning and using. POA believes that language education is aimed for people, who have emotions and thoughts. In order to provide comprehensive services for people, education needs to take into account all 
aspects of human intelligence, emotion and morality. Specifically, foreign language courses must not only achieve the instrumental goals of improving students' ability to use English comprehensively, but also achieve the humanistic goals of higher education, such as improving students' critical thinking ability, self-learning ability, and comprehensive cultural literacy. Therefore, teacher needs to carefully choose the topics of the production task, which can either help students establish a correct world view, outlook on life and values or promote the ability of students to exchange Chinese and foreign cultures and spread Chinese culture. Also, to achieve the production tasks, teacher needs to carefully select the input materials that can both cultivate the students' sentiment and reflect the social and political hot topics at home and abroad to broaden their international horizons. Besides, teacher needs to smartly design the organizational form of teaching activities. For example, teachers can cultivate students' cooperation spirit through pair work or group activities, and improve students' ability to objectively evaluate others' advantages and disadvantages by evaluating each other's production.

\section{B. Teaching Hypotheses of POA}

The POA teaching hypotheses consist of three parts: output-driven hypothesis, input-enabled hypothesis and selective learning hypothesis.

Krashen put forward an input hypothesis, which emphasized the importance of comprehensible input for second language acquisition, ignoring the role of output [4]. Swain's output hypothesis acknowledged the importance of input but deemed the output as an even more indispensable part of language acquisition. She discussed three functions of output, which are: the 'noticingltriggering' function, or its consciousness-raising role, the hypothesis-testing function, and the metalinguistic function, or its reflective role [5]. However, what she did not explicitly mention was that at different stages of learning, input need to be driven by output. Long's interaction hypothesis illustrated that corrective feedback helped learners learn correctly during the activity process, but he also did not reveal the reaction of the output to the input. Based on these hypotheses, Wen puts forward the outputdriven hypothesis, which advocates that output is both the driving force of language learning and the goal of language learning and output is more effective than input in stimulating students' learning desire and learning enthusiasm. With the output task as the starting point of teaching, the students can realize the communicative value of output to improve the cultural literacy, complete the study and improve the future work after they try to complete the output task. Even more importantly, they can realize their language deficiency thus enhancing the sense of urgency of learning. This hypothesis believes that once the students have realized the meaning of the output task and their own deficiencies, they will be more proactive in carrying out input learning in order to complete the output tasks to make up for their own shortcomings [1].

The input-enabled hypothesis suggests that under the conditions of output-driven, the right input can achieve better learning results than if it is not provided. If teachers are able to provide appropriate input materials based on student interaction, these materials can act as “experts lead”, effectively expanding students' existing knowledge and language systems, and encourage better quality output.

The selective learning hypothesis refers to the selection of useful parts from input materials for deep processing, practice, and memory based on output needs. This hypothesis suggests that selective learning optimizes learning results more than non-selective learning. The conditions for learning foreign languages have improved a lot, especially in English, where input is almost everywhere. As long as the students want to learn, they can find a lot of materials anytime anywhere, therefore it's especially important for teacher to select materials for students when they are faced with tons of language materials and limited classroom hours.

\section{Teacher-mediated Teaching Process of POA}

There are three key procedures in the teacher-mediated teaching process of POA. Procedure one: motivating, that is, the teacher designs appropriate communicative scenarios and tasks with potential communicative value to stimulate the enthusiasm of the students to complete the task, enhancing the motivation of learning; Procedure two: enabling, that is, the teacher provides the necessary input materials, and guides the students to obtain the language, content and discourse structure needed to complete the task through the selection and processing of the listening and reading materials; Procedure three: assessing, that is, the student completes the production tasks, and the teacher provides evaluation and remedial teaching. All the three procedures must be mediated by teacher, who's main job is to guide, design and scaffold, etc.

There are three steps in motivating: 1) Teacher presents communicative scenarios; 2) students attempt to produce; 3) teacher explains teaching objectives and production tasks. The most creative and most challenging part of POA lies in step one, where the teacher presents communicative scenarios. The teacher is supposed to present students with the topic of communication and discussion that they may encounter in their future study and work. These scenes may not have been experienced by students, but they can truly feel the "possibility" of these scenes and the challenges of their cognition in the topics to be discussed in these scenes. The second step allows students to experience first-hand that it is not easy to accomplish such seemingly simple and usual production tasks, thus creating pressure and motivation for them to learn. As for the teaching objectives in step three, there are two categories. The first category is the communicative objective, which is to accomplish a certain kind of communicative task; the second is the language objective, which is to master certain words, phrases or grammar knowledge. As for the production tasks, they can be divided into two categories: in-class tasks and after-class tasks according to different time of completing the tasks. The inclass tasks refer to the production exercises that are synchronized with the input learning. The after-class tasks refer to the production practice that the teacher asks the students to complete after the class. The after-class tasks can be further divided into review tasks and shifting tasks based on the difficulty of accomplishing them. 
There are also three steps in enabling. 1) The teacher describes the production tasks; 2) the students conduct selective learning while the teacher guides and checks; 3) the student accomplish the production tasks while the teacher guides and checks. In order to reduce the difficulty of the production task and bridge the gap between production and input learning, teachers often break down a large production task into several subtasks. How does POA guide selective learning? Successful completion of a production task requires at least the content, the language, and the discourse structure. According to the principle of selective learning, there should be different focus in different step of learning. When the teacher guides the students to process the input materials, whether the student chooses the content, the language form or the discourse structure, the teacher needs to give an instant check on whether the result of the selection is appropriate, so as to understand the effectiveness of the students' selective learning. Vygotsky points out that any thought has movement. It unfolds. However, there are moments when such unfolding gets stuck. That's when learners need support. The idea of teacher's support is closely connected to the notion of scaffolding, which in its original sense refers to a more capable person offering temporary support, helping learners to perform tasks that they could not (yet) complete by themselves [7]. What are the features of scaffolding in teacher-student interactions? Vygotsky thinks of scaffolding as closely related to constructivist theories. Likewise, it should not be conceived as merely targeted at outcomes. In fact, scaffolding exists all the way through the process of active knowledge construction. Therefore, teachers need to adopt the learners' perspectives, diagnose their current level of understanding and, get involved in their cognitive processes and co-constructive activity if necessary. Hence, scaffolding composes two major characteristics: 1) dynamic assessment: To ascertain the right amount of support and appropriate content, the teacher needs to find out about the current state of the student's understanding and knowledge construction. 2) procedural facilitation Intervening neither too strongly nor too weakly [8]. The teacher's scaffolding role is most obvious in the procedure of enabling. On the one hand, the teacher should decide how much to help on the basis of fully understanding the students' learning situation. Who should do scaffolding and the way to provide scaffolding must conform to the language level of students. Too much help is not conducive to the development of students' learning autonomy, while the deficiency of help will limit learning efficiency. Therefore, teachers should consciously and gradually reduce their scaffolding role, and gradually improve students' sense of learning responsibility [9].

The assessing of production can be divided into in-class assessing and after-class assessing since it is appropriate to check the production of all students in the class with limited and valuable hours.

\section{Comparison of POA with Task-based Language Teaching}

Task-based language teaching has become very popular in the field of second language acquisition in that it fosters process-focused syllabi and devises communicative tasks to enhance learners' real language use via the emergence of the communicative language teaching approach in the early 1980s and much stress on learners' communicative abilities during the past decades [10]. Although the advocates of task-based language teaching have not agreed on its core principles, there is a general agreement among them on the following characteristics: 1) Instructed language learning should mainly contain natural or naturalistic language use, and the activities are related to meaning rather than language. 2) Instruction should support learner-centeredness rather than teachercenteredness. 3) Because totally naturalistic learning does not normally give rise to target-like accuracy, engagement is essential to promote the internalization of formal linguistic elements while keeping the perceived benefits of a natural approach. 4) This can be realized best by offering opportunities for focus on the form, which will attract students' attention to linguistic components as they emerge incidentally in lessons whose main focus is on meaning or communication. 5) Communicative tasks are especially suitable devices for such an approach. 6) More formal pre- or post-task language study may be beneficial. This may make contribution to internalization by leading or maximizing familiarity with formal characteristics during communication. 7) Traditional approaches are unproductive and unsuitable, particularly where they require passive formal instruction and practice isolated from communicative work [10]. When the writer makes a comparison between POA and task-based language teaching in terms of teaching principles, hypotheses and procedures, it has been found that, in terms of teaching principles, both approaches highly val $\neg$ ue the principles of "whole person education" and "learning in using”, but they differ in that POA emphasizes the "learning-centered principle" while task-based language teaching advocates "learner-centered principle". As for teaching hypotheses, they both put emphasis on the effect of input and out $\neg$ put, but differ in that POA highlights the integration of input and output while task-based language teaching emphasizes output with less attention to input.

\section{APPLICATION OF POA IN COLLEGE ENGLISH TEACHING}

As a college English teacher in Xiamen University Tan Kah Kee College (TKKC), the writer applies POA in class for experiment. A teaching plan for a lesson is designed and put into teaching after repeated revision and improvement.

\section{A. Teaching topic and Objectives}

The writer selects the topic of "money management" with two teaching objectives: language and culture. Language objectives include: twelve basic words and eight expressions, and if-conditional sentence to talk about money management as college students and to design and conduct a survey regarding spending habits of college students. Cultural objectives aim to cultivate students' cross-cultural abilities including realizing different economic independence between Chinese college students and western college students.

\section{B. Teaching Procedures}

The writer strictly follows the three teaching procedures of POA, which are motivating, enabling and assessing.

Designing tasks with potential communicative value and motivating students to learn are the starting point of POA. So 
the teacher invites students to imagine the situations when they might talk about financial situations with friends and when they might be asked to design and conduct a survey about people's spending habits, thus arousing their interest in the topic. Then the teacher assigns two tasks. Task one: work in groups and try to help an imaginary friend Tom to manage his money. Tom, a freshman in Xiamen University majoring in architecture, gets RMB800 from his parents per month and works part-time in the school café as a waiter, making RMB 400 per month. With RMB 1,200 at his disposal each month, how can he manage his money so that he won't run out of money before the end of the month or run into any money trouble. Task two: work in pairs, design and conduct a survey about college students' spending habits, make a video of the survey, and write a report.

In the enabling procedure, teacher is supposed to fully play a mediating role in guiding students to select appropriate input materials to facilitate the completion of production tasks. For task one, the teacher plays a two-minute video clip from the movie "Confessions of a Shopaholic" and plays a one-minute video from the speaking listening and viewing text book after briefly explaining some key expressions like keep a budget, priority, credit card, broke, emergency, give me a loan, save up for, emergency, and deep in debt. After playing each video, the teacher invites two students to recount what happens in the video, using the key expressions provided, and asks the whole class to complete task one - working in groups and talking about how Tom can manage his money. Task two- designing and conducting a survey about college students' spending habits- is further divided into three sub-tasks. Sub-task one: the teacher asks students to take a look at a survey in the reading and writing text book first, work in pairs and take turns interviewing each other on the five survey questions after the teacher explains cultural differences between Chinese college students and western college students in terms of main sources of expenses for college students. After that, the teacher invites two pairs to compare their answers and specify what they have in common and how they are different. Sub-task two: the students are encouraged to brainstorm and work out a survey of no less than five questions regarding the spending habits of TKKC students. While the students are trying the work out the survey, the teacher walks around to provide assistance either in coming up with ideas or in finding the right English expressions for their Chinese ideas. This is where the teacher plays the role of scaffolding, keeping in mind that too much help is not conducive to the development of students' learning autonomy, while the deficiency of help will limit learning efficiency. Sub-task three: the students are assigned an afterschool task to make a video of interviewing at least five students randomly on campus with the survey questions they design in class.

The assessing procedure of POA aims to help the teacher understand the effectiveness of teaching through the assessing of students' production; at the same time, it helps students to understand the learning outcomes and further improve their production quality. Therefore, the assessing procedure has the effect of "promoting learning". For task one, one representative from each group is asked to present their ideas in class, the teacher then comments on their presentation, focusing on the good ideas and suggestions for improving the language expressions. For task two, after the students submit the videos they make of interviewing at least five students randomly on campus with the survey questions they design, each group has to assess others' production work by both grading each video and commenting on the excellent part and areas to be improved in each video.

\section{TEACHING REFLECTION}

After the experiment of POA in class, the writer has some subjective feelings about its teaching effects and has observed some difficulties in the application. Hopefully some inspirations will be offered to other teachers for reference.

\section{A. The Teaching Effect of POA}

In the process of teaching experiments, the writer clearly feels the vitality brought by POA to the classroom. First, POA stimulates a positive emotional experience for students. Instead of the "input-output" process, the "output-input-output" mode arouses students' interest more effectively, and students feel that what they have learned is "useful". Second, the teachermediated "enabling" also reduces the anxiety of students when they try to complete tasks, and at the same time allows students to achieve "successful feelings" in the process of completing tasks. The writer believes that a positive emotional experience is one of the advantages of POA. Third, students gain more opportunities to use the language with POA. In the implementation of POA, each task is divided into smaller tasks, each of which offers an opportunity to use the language, such as speaking about how to manage money, designing a survey and interviewing students about their spending habits. In this way, creating more language use opportunities through flexible means in the classroom can promote the transfer of students' acceptive knowledge to productive knowledge.

\section{B. Difficulties in the Implementation of POA}

Among all the difficulties in the application of POA in classroom, the biggest one lies in the challenge for teacher as it's both time-consuming and demanding in designing tasks which have to be both of practical use and of communicative value. Another difficulty is for teachers to balance the role of teacher scaffolding and the motivation of student autonomy, as too much assistance is not conducive to the development of students' learning autonomy, while the deficiency of help will limit learning efficiency, but the whole class is not at the same language level, thus teachers have to identify different levels of different students and provide the appropriate amount of assistance while students are trying to produce. Still another difficulty lies in the selection of input materials, as they have to be both related to and conducive to production tasks and in various forms.

\section{CONCLUSION}

POA emphasizes the role of production in language learning and introduces the idea of integrating input and output in language teaching, providing a new teaching idea to improve the efficiency of college English classroom teaching in China. The writer makes a preliminary attempt in this approach in the 
classroom, which initially confirms the feasibility of this approach. The teaching effects are positive but difficulties exist. Due to various reasons, the writer's teaching design is not mature enough, many details remain yet to be improved, and many difficulties and problems may not have been exposed. Hope more foreign language teachers can make classroom experiments, and improve the classroom design of POA.

\section{REFERENCES}

[1] Wen, Qiufang. Developing a theoretical system of production-oriented approach in language teaching. Foreign Language Teaching and Research 2015:547-558. In Chinese

[2] Kirschner, P., Sweller,J. \& Clark, R. Why minimal guidance during instruction does not work: An analysis of the failure of constructivist, discovery, problem-based, experiential, and inquiry-based teaching. Educational Psychologist 2006: 75-86.
[3] Mercer, N. \& Dawes, L. The study of talk between teachers and students, from the1970s until the 2010s. Oxford Review of Education 2014: 430445.

[4] Krashen, S. The Input Hypothesis: Issues and Implications. London: Longman. 1985.

[5] Swain, M. Three functions of output in second language learning. In G. Cook \& B. Seidlhofer (eds.). Principles and Practice in Applied Linguistics: Studies in Honor of H. G. Widdowson. Oxford; OUP1995. 125-144.

[6] Long, M. The role of the linguistic environment in second language acquisition. In W. Ritchie \& T. Bhatia (eds.). Handbook of Second Language Acquisition. San Diego: Academic Press. 1996: 413-468.

[7] Vygotsky, L.S. In R.W. Rieber, \& A. S. Carton (Eds.), The collected works of L. S. Vygotsky (Vol. 1.). New York: Plenum. 1987.

[8] Hermkes, R. Mach, H. \& Minnameier, G. Interaction-based coding of scaffolding processes. Learning and Instruction. 2018:147-155.

[9] Van de Pol, J. Monique \& Jos. B. Scaffolding in teacher student interaction: A decade of research. Educational Psychological Review 2010: 271-296.

[10] Hismanoglu, M\& Hismanoglu, S. Task-based language teaching: what every EFL teacher should do. Procedia Social and Behavioral Sciences 2011: 46-52. 